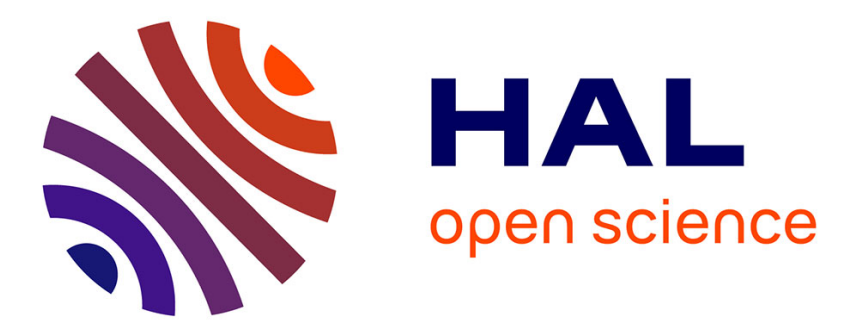

\title{
Intraspecific trait variability mediates the response of subalpine grassland communities to extreme drought events
}

Vincent Jung, Cécile H. Albert, C. Violle, G. Kunstler, G. Loucougaray, T. Spiegelberger

\section{To cite this version:}

Vincent Jung, Cécile H. Albert, C. Violle, G. Kunstler, G. Loucougaray, et al.. Intraspecific trait variability mediates the response of subalpine grassland communities to extreme drought events. Journal of Ecology, 2014, 102 (1), pp.45-53. 10.1111/1365-2745.12177 . hal-00949680

\section{HAL Id: hal-00949680 https://hal.science/hal-00949680}

Submitted on 24 Feb 2014

HAL is a multi-disciplinary open access archive for the deposit and dissemination of scientific research documents, whether they are published or not. The documents may come from teaching and research institutions in France or abroad, or from public or private research centers.
L'archive ouverte pluridisciplinaire HAL, est destinée au dépôt et à la diffusion de documents scientifiques de niveau recherche, publiés ou non, émanant des établissements d'enseignement et de recherche français ou étrangers, des laboratoires publics ou privés. 
1 Intraspecific trait variability mediates the response of subalpine grassland

2 communities to extreme drought events

3

4 Vincent Jung ${ }^{1,2 *}$, Cécile H. Albert ${ }^{3,4}$, Cyrille Violle ${ }^{5,6}$, Georges Kunstler ${ }^{1,7}$, Grégory

5 Loucougaray $^{1} \&$ Thomas Spiegelberger $^{1,8}$

6

$7 \quad{ }^{1}$ Irstea, UR Mountain Ecosystems, St-Martin-d'Hères, France

$8{ }^{2}$ CNRS UMR 6553, ECOBIO, Université de Rennes 1, Rennes, France

$9{ }^{3}$ Laboratoire d'Ecologie Alpine, CNRS UMR 5553, Université Joseph Fourier, Grenoble,

10 France

$11{ }^{4}$ Department of Biology, McGill University, Montreal, Quebec, Canada

$12{ }^{5}$ Department of Ecology and Evolutionary Biology, University of Arizona, Tucson, USA

$13{ }^{6}$ Centre d'Ecologie Fonctionnelle et Evolutive, CNRS UMR 5175, Montpellier, France

$14{ }^{7}$ Department of Biological Sciences, Macquarie University, Sydney, NSW 2109, Australia

$15{ }^{8}$ Ecole Polytechnique Fédérale de Lausanne (EPFL), Laboratory of Ecological Systems

16 (ECOS) - Swiss Federal Institute for Forest, Snow and Landscape Research (WSL), Research

17 Group Restoration Ecology, station 2, CH-1015 Lausanne, Switzerland

18 | ${ }^{*}$ Correspondence author. E-mail: vincent.jung@univ-rennes1.fr

19

20 Running headline: Extreme droughts in subalpine grasslands 


\section{Summary}

1. Climate change is expected to increase the magnitude and the frequency of extreme climatic events such as droughts. Better understanding how plant communities will respond to these droughts is a major challenge. We expect the response to be a shift in functional trait values resulting from both species turnover and intraspecific trait variability, but little research has addressed the relative contribution of both components.

2. We analysed the short-term functional response of subalpine grassland communities to a simulated drought by focusing on four leaf traits (LDMC: leaf dry matter content, SLA: specific leaf area, LNC: leaf nitrogen concentration, LCC: leaf carbon concentration). After evaluating species turnover and intraspecific variability separately, we determined their relative contribution in the community functional response to drought, reflected by changes in community weighted mean traits.

3. We found significant species turnover and intraspecific variability, as well as significant changes in community weighted mean for most of the traits. The relative contribution of intraspecific variability to the changes in community mean traits was more important (42-99\%) than the relative contribution of species turnover (1-58\%). Intraspecific variability either amplified (for LDMC, SLA and LCC) or dampened (for LNC) the community functional response mediated by species turnover. We demonstrated that the small contribution of species turnover to the changes in community mean LDMC and LCC was explained by a lack of covariation between species turnover and interspecific trait differences.

4. Synthesis. These results highlight the need for a better consideration of intraspecific variability to understand and predict the effect of climate change on plant communities. While both species turnover and intraspecific variability can be 
expected following an extreme drought, we report new evidence that intraspecific

2 variability can be a more important driver of the sort-term functional response of plant

3 communities.

4

5 Key_words: climate change experiments, community weighted mean traits, drought,

6 grasslands, intraspecific variability, plant-climate interactions, plant functional traits 


\section{Introduction}

2 Extreme weather events are projected to increase in magnitude and in frequency due to climate change (Easterling et al. 2000; IPCC 2007), calling for a shift from 'trend-focused' to 'event-focused' climate change experiments (Jentsch et al. 2007). Summer droughts and in

5 particular extreme drought events are expected to be among the main consequences of climate 6 change (Meehl \& Tebaldi 2004). Understanding the mechanisms that underlie the response of 7 communities to such droughts is a major challenge for predicting climate change effects on biodiversity (Smith 2011). Plants, as sessile organisms, are likely to be particularly exposed to an increasing frequency of extreme droughts.

Drought represents a strong abiotic filter (Chase 2007) that restricts trait range within communities to a limited set of values (e.g. Cornwell \& Ackerly 2009). The regulation of water loss through leaves can be expressed by several key leaf functional traits (Wright et al. 2001; Ackerly 2004) and, for example, be reflected through higher leaf dry matter content (LDMC) and/or lower specific leaf area (SLA) (Buckland et al. 1997; Volaire 2008; Poorter et al. 2009). Therefore, drought events are expected to shift community trait composition. A change in trait composition within a community through time can be caused by a change in species composition and/or relative abundance ('species turnover' hereafter, used in a broad sense including both qualitative and quantitative changes), by intraspecific trait variability ('intraspecific variability' hereafter) or by any combinations of these factors (Lep et al. 2011; Violle et al. 2012; Albert et al. 2012). Community functional response to drought can be evaluated through the analysis of community weighted mean traits (i.e., the mean of trait

22 values weighted by the relative abundance of each species in the community, Garnier et al. 2004; Violle et al. 2007, 'community mean trait' hereafter), the variation of which is able to capture trait shifts due to both species turnover and intraspecific variability. Up to now, while 
1 focused on species turnover (e.g. Evans et al. 2011; Kreyling et al. 2011) or on changes in

2

community mean traits driven by species turnover (e.g. Sandel et al. 2010). Intraspecific variability in response to climate changes was investigated for many species individually (e.g Buckland et al. 1997; Hudson et al. 2011; Weißhuhn et al. 2011; West et al. 2012), but the contribution of intraspecific variability in changes in community mean traits has been largely overlooked. However, recent studies have started to shed some light on the importance of intraspecific variability for community functional responses to environmental changes (Jung et al. 2010; Andersen et al. 2012; Violle et al. 2012; Albert et al. 2012).

The relative contribution of intraspecific variability vs. species turnover in driving community response to environmental change is likely to vary with the timescale under scrutiny (Smith et al. 2009; Sandel et al. 2010). For instance short-term events such as extreme droughts are likely to induce community functional responses mainly via intraspecific variability through plastic adjustment of the resident plants (Helmuth et al. 2005), while long-term progressive changes are likely to impact communities mainly by species turnover (Teurillat \& Guisan 2001; Jump \& Peñuelas 2005; Helmuth et al. 2005). For the stability of plant communities in response to drought events, assessing the relative contribution of intraspecific variability $v s$. species turnover to community functional responses is thus a crucial question. However surprisingly few studies have explored this question.

In this study, we address the question of the relative contribution of intraspecific variability to community weighted mean traits by examining the short-term functional response of subalpine grassland communities to a simulated drought. We focus on four key functional leaf traits known to be related to species water use strategy (Wright et al. 2001; Chaves et al. 2002; Ackerly 2004; Weih et al. 2011): specific leaf area, leaf dry matter content, leaf nitrogen concentration and leaf carbon concentration. We address two main 
1 questions: (i) how does drought modify species abundances and species trait values? (ii) what

2 is the relative contribution of species turnover and intraspecific variability in driving the

3 short-term community functional response to drought?

4

5 
Materials and $\underline{\operatorname{methods}}$

2

3 Study area

4 The study site ( $44^{\circ} 51 \mathrm{~N}, 5^{\circ} 28 \mathrm{E}, 1500 \mathrm{~m}$ a.s.1.) is situated in the Hauts-Plateaux du Vercors

5 Nature Reserve which is part of the Long-Term Socio-Ecological Research (LTSER) platform

6 "Central French Alps". The geological substrate consists of highly permeable karstic

7 limestone. The vegetation is a mosaic of dry grasslands and woody patches of Juniperus

8 communis (L.), Picea abies (L.) and Pinus uncinata (Ramond ex DC.). Grassland

9 communities are species-rich and composed of perennial species, dominated by

10 hemicryptophyte life forms (90\% of the total abundance) with either persistent or summer 11 green leaves (65\% and $35 \%$ of the total abundance, respectively, Klotz et al. 2002). The

12 dominant species are Carex sempervirens (Vill.), Festuca laevigata (Gaudin) and Festuca

13 nigrescens (Lam.) (see Table S1 in Supporting Information). The studied subalpine grassland 14 has been grazed by sheep since the Middle Ages. Currently it is extensively grazed each year 15 by sheep during the plant growing season, from mid-June until the end of September. During the experiment, the study area was protected from grazing by fencing. The study area is covered by snow for approximately $5-6$ months of the year (December-May).

\section{Rainfall manipulation}

20 An extreme drought event was simulated during peak vegetation growth in summer 2010 by

21 exclusion of ambient rainfall through four semi-cylindrical rainout shelters. The shelters

22 (length: $8 \mathrm{~m}$; width: $4 \mathrm{~m}$; height: $2.5 \mathrm{~m}$, c. $30 \mathrm{~m}$ distant from each other) were covered with a

23 transparent polyethylene roof with open sides to allow air circulation. Air moisture and

24 temperature were not significantly altered by this system (EHT humidity/temperature sensor, 
1 Decagon Devices, Pullman, Washington, USA, data not shown). Shelters were fenced to

2 prevent access to sheep during the experiment.

Rain shelters covered both drought and control plots. Six $0.60 \times 0.60 \mathrm{~m}$ plots (three control plots / three drought plots) were randomly located under each shelter (total 24 plots), by ensuring at least $1.20 \mathrm{~m}$ spacing between plots and at least $60 \mathrm{~cm}$ spacing from the edge of the shelter. In order to prevent rain water from accumulating at the edge of the shelters, rain falling on the roof of the shelters was collected thanks to gutters connected to $300-\mathrm{L}$ tanks and was used to water the control plots. Control plots were watered twice a week following the local June-July average rainfall over the 1952-2009 period (data: meteorological station of Météo-France, La Chapelle en Vercors, c. 10km distant from the study area). Drought plots were not watered from 7 June to 12 July 2010, corresponding to a rainfall deficit of $115 \mathrm{~mm}$ (62\%) from the June-July average rainfall (see Fig. S1). Drought with this intensity used to correspond to a 30-years return period of the simulated drought based on the 1952-2009 data. This return period is projected to decrease to 10 years for $2050-2100$ under the B1 scenario (IPCC 2007, climate projection simulations from the Hadley Centre model HADCM3, Fig. $\mathrm{S} 1)$. The average volumetric soil water content during the experiment was $6 \%(3 \% \mathrm{SD})$ in the drought plots, against $17 \%(4 \% \mathrm{SD})$ in the control plots $\left(\mathrm{ECH}_{2} \mathrm{O}\right.$ soil moisture sensor, Decagon Devices, Pullman, Washington, USA).

\section{Data collection}

21 Plant species were recorded twice, immediately before (3-4 June) and after (15-16 July) the drought event. All species were recorded within each plot and the relative abundance of each species was obtained by the "point-quadrat" sampling (Levy \& Madden 1933), a suitable method for the calculation of community-weighted mean traits (Lavorel et al. 2008). For a 
1 given plot, the local abundance of each species was determined as the number of hits among

216 sampling points evenly distributed within the plot. Leaf traits were measured in each plot for the most abundant species, i.e. species for which the cumulated relative abundance reached at least $80 \%$ of the plot total abundance (Pakeman \& Quested 2007). Leaves were collected at the end of the drought event (8-16 July) on three individuals of each species per plot. The youngest fully expanded leaf was sampled for each individual. Specific leaf area (SLA, the ratio of fresh leaf area to leaf dry mass, $\mathrm{m}^{2} \cdot \mathrm{kg}^{-1}$ ) and leaf dry matter content (LDMC, the ratio of leaf dry mass to leaf fresh mass, g. $\mathrm{kg}^{-1}$ ) were measured after complete rehydration of leaves (Garnier et al. 2001a). Leaf nitrogen concentration ( $\mathrm{LNC}$, the ratio of total nitrogen to leaf dry mass, $\mathrm{g} \cdot \mathrm{kg}^{-1}$ ) and leaf carbon concentration (LCC, the ratio of total carbon to leaf dry mass, g. $\mathrm{kg}^{-1}$ ) were analysed with FlashEA 1112 elemental analyzer (Thermo Fisher Scientific Inc., Milan, Italy). For a given species, data were averaged per plot, thus accounting for intraspecific variability between plots.

\section{Drought-induced species turnover and intraspecific variability}

Bray-Curtis dissimilarity in species composition between drought and control plots was used to evaluate the species turnover due to drought. Species abundances were aggregated across drought or control plots and then converted in relative abundance or presence/absence. The Bray-Curtis dissimilarity between drought and control plots was calculated before and after the drought event, from relative abundance and presence-absence data. We used the 'vegdist' procedure in the vegan package of $\mathrm{R}$ version 2.11.1 ( $\mathrm{R}$ Development Core Team 2010). To identify which species contributed to species turnover we estimated the effect of drought on each species by calculating the difference in relative abundance $(\mathrm{Ab})$ between drought and control plots. Statistical significances for Bray-Curtis dissimilarity and Ab were evaluated 
1 using a permutation test (10000 permutations) wherein treatments (control/drought) were

2 randomly reassigned to plots separately within each shelter.

In order to compare the different sources of variability in raw trait values, we used

nested linear models to decompose the total variance of each trait into hierarchical

components, as described in Messier et al. (2010). For each trait, the total variance was

decomposed into three variance components: 'among species' (i.e. interspecific trait differences), 'among treatments within species' (i.e. intraspecific variability explained by the drought treatment) and 'among plots within treatments' (i.e. unexplained intraspecific variability). We assessed the effect of drought on each trait over all species and for each species independently by using mixed GLM including 'shelter' as a random effect.

\section{Community functional response to drought}

In order to capture the drought-induced community functional response, we calculated the community mean for each trait and each plot, as the mean of trait values in the plot weighted by the relative abundance of each species (Garnier et al. 2004; Violle et al. 2007). As changes in community mean traits account for both species turnover and intraspecific variability, we disentangled their relative contributions. We calculated community mean traits within each plot from species relative abundances and trait values recorded in their respective plot. We recalculated community mean traits in drought plots from species abundances in drought plots but the trait values measured in control plots and averaged by species, i.e. under the hypothesis of a lack of intraspecific variability. We quantified the contributions of species

22 turnover and intraspecific variability in the response of community mean traits to drought

$23\left(\mathrm{C}_{\text {Turn }}\right.$ and $\mathrm{C}_{\text {Intra }}$, respectively), as: 
eq. 2

2

where $\mathrm{T}_{\mathrm{Ct}}$ and $\mathrm{T}_{\mathrm{Dr}}$ are the observed community mean traits averaged by treatments (Control/Drought), and $\mathrm{T}_{\mathrm{Dr}^{*}}$ is the average of community mean traits recalculated in drought plots by using species trait values in control plots. $\mathrm{C}_{\text {Turn }}$ and $\mathrm{C}_{\text {Intra }}$ represent the isolated effects of species turnover and intraspecific variability, respectively, in driving the response of community mean traits to drought. We used mixed GLMs with 'shelter' as random effect to test the significance of the drought-induced shift in the average community mean traits between control and drought plots (i.e., $\mathrm{T}_{\mathrm{Dr}}$ vs. $\mathrm{T}_{\mathrm{Ct}}$ and $\mathrm{T}_{\mathrm{Dr}^{*}} \mathrm{vs} . \mathrm{T}_{\mathrm{Ct}}$ ), as well as the significance of the effects of intraspecific variability in the drought plots (i.e., $\mathrm{T}_{\mathrm{Dr}^{*}} \mathrm{vs} \mathrm{T}_{\mathrm{Dr}}$ ). Finally, we determined the extent to which we could have expected $\mathrm{C}_{\text {Turn }}$ and $\mathrm{C}_{\text {Intra }}$ to be greater than we found, given the observed levels of species turnover and of intraspecific variability. In order to explore the way traits interact with species abundances to determine $\mathrm{C}_{\text {Turn }}$ and $\mathrm{C}_{\text {Intra }}$, we generated random distributions of $\mathrm{C}_{\text {Turn }}$ and $\mathrm{C}_{\text {Intra }}$ from a dataset comprising, for each species and each trait, a pair of abundance values (i.e. the averages in the control treatment and in the drought treatment) and the corresponding pair of trait values.

Pairs of trait values were randomly reallocated to pairs of abundance values, and each trait or abundance value within a pair was randomly reallocated to treatments. This procedure allowed us to randomize trait values with respect to abundance values while maintaining the magnitude of the observed inter- and intraspecific differences. For each trait we generated a random distribution of $\mathrm{C}_{\mathrm{Turn}}$ and of $\mathrm{C}_{\text {Intra }}$ from 10000 permutations. We used these distributions to calculate the proportion of the simulated values of $\mathrm{C}_{\mathrm{Turn}}$ or of $\mathrm{C}_{\text {Intra }}$ that is higher, in magnitude, than the observed value, as:

$\mathrm{P}_{|\operatorname{sim}|>|\mathrm{obs}|}=\mathrm{N}\left(\left|\operatorname{simC}_{x}\right|>\left|\operatorname{obsC}_{x}\right|\right) / 10000 \quad$ eq. 3

where $\mathrm{N}\left(\left|\operatorname{simC}_{x}\right|>\left|\operatorname{obsC}_{x}\right|\right)$ is the number of time the magnitude of the simulated values of $\mathrm{C}_{\text {Turn }}$ (or of $\mathrm{C}_{\text {Intra }}$ ) is higher than the observed value. For $\mathrm{C}_{\text {Turn }}, \mathrm{P}_{|\operatorname{sim}|>\mid \text { obs } \mid}$ close to 0 indicates 
1 that species turnover covaries with interspecific trait differences, leading to the highest

2 magnitude that $\mathrm{C}_{\text {Turn }}$ could potentially reach given the observed trait and abundance values.

3 For $\mathrm{C}_{\text {Intra }}, \mathrm{P}_{|\operatorname{sim}|>\mid \text { obs } \mid}$ close to 0 indicates that intraspecific trait response covaries with species

4 abundances, leading to the highest magnitude that $\mathrm{C}_{\text {Intra }}$ could potentially reach.

5 


\section{Results}

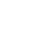

\section{Species turnover}

Before the drought event, we found no significant difference between drought and control plots in terms of species composition (Bray-Curtis dissimilarity; Fig. 1a, b). Drought significantly shifted species' relative abundance (Fig. 1a), but not species' presence-absence (Fig. 1b). The relative abundance of Festuca laevigata and Hieracium pilosella (L.) significantly increased due to drought, whereas the relative abundance of Ranunculus montanus (Willd.), Trifolium pratense (L.), Agrostis capillaris (L.) and Festuca nigrescens significantly decreased (Fig. 2).

\section{Intraspecific variability}

We performed a variance component analysis in order to examine the relative contribution of species, treatment and plot identity to the total variance in raw trait values. This analysis revealed that, on average, intraspecific variance accounted for $27 \%$ of the total trait variance and that most of the trait variance (73\%) was due to differences between species (Fig. 3).

Moreover, only $7 \%$ of the total trait variance was due to intraspecific variance between treatments, while $20 \%$ was due to intraspecific variance within treatments.

We found a significant intraspecific trait response to drought among all species for all traits except SLA (Fig. 4), as well as significant individual species responses in 12 species for LDMC and in $\underline{4}$ species for SLA, LNC and LCC (Fig. 4). However, changes in individual species responses did not show a unidirectional pattern. For example, five species showed a significant decrease in LDMC, thus going against the prevailing trend. 
1 Community mean traits significantly increased in response to drought for LDMC (Fig. 5a)

2 and LCC (Fig. 5d), and significantly decreased for SLA (Fig. 5b). Intraspecific variability

3 significantly contributed to the changes in community mean LDMC, SLA and LCC, and

4 accounted for $48 \%$ to $99 \%$ of these changes; species turnover only contributed significantly to

5 the community response for SLA (Fig. 5b). The direction of intraspecific variability effects on

6 community mean traits were in accordance with the prevailing trends in trait responses

7 observed in Fig. 4. Community mean LNC was unaffected by drought through a

8 compensatory effect of intraspecific variability on species turnover (Fig. 5c).

The comparison of observed vs. simulated contributions of species turnover and of

10 intraspecific variability revealed that in many cases, the magnitude of the simulated

11 contributions largely exceeded the observed magnitude (Fig. 6). The amount by which the

12 magnitude of the simulated contributions exceeded the observed magnitude (i.e. $\mathrm{P}_{|\operatorname{sim}|>|\operatorname{obs}|}$ )

13 differed between traits and between species turnover and intraspecific variability. In

14 particular, for LDMC and LCC $\mathrm{P}_{|\operatorname{sim}|>|\mathrm{obs}|}$ was higher for species turnover than for intraspecific

15 variability, whereas for SLA and $\operatorname{LNC} \mathrm{P}_{|\operatorname{sim}|>|\operatorname{obs}|}$ was higher for intraspecific variability. 


\section{Discussion}

2 We have studied the immediate functional response of herbaceous communities to an extreme

3 drought event, in contrast to long-term experiments that addressed the impact of mean climate

4 change (e.g. Grime et al. 2008; Hudson et al. 2011). We particularly addressed the

5 contribution of intraspecific variability in mediating trait shifts within communities.

6 Intraspecific variability can result from genetic variability and phenotypic plasticity. Here we

7 evaluated the overall intraspecific variability induced by drought regardless of its underlying

8 cause. Given the short-term period under scrutiny, intraspecific variability recorded here is

9 probably mainly due to plastic physiological adjustments.

Species turnover and intraspecific variability in response to drought

12 Although drought induced a significant species turnover, this was due to changes in the relative abundance of species rather than in the identity of species. This result is obviously related to the short period of our experiment during which drastic compositional changes due to species replacements were not likely to occur. However, this may also reflect the existence of stabilizing processes such as reduced adult mortality that minimize the short-term effect of drought on plant species composition (Lloret et al. 2012).

Whatever the trait under scrutiny, most of the variance in raw trait values was explained by differences between species, in accordance with the general agreement that traits vary more between than within species (Garnier et al. 2001b). Though intraspecific variance accounted for a smaller part of the total variance, interestingly most of it occurred among

22 plots within treatments rather than between treatments. This corroborates the findings of Albert et al. (2010) that the most important proportion of the intraspecific variance of LDMC occurred at a fine spatial scale rather than between different locations along strong abiotic gradients. The high level of intraspecific variance within treatments can be related to the high 
1 fine-scale soil heterogeneity due to irregularities of the bedrock surface in the study area.

2 (Fridley et al. 2011). The low intraspecific variance between treatments suggests that the level

3 of intraspecific variability involved in the response to drought did not exceed the level that is usually expressed in response to spatial environmental micro-heterogeneity.

The drought treatment induced significant intraspecific trait responses over all species.

The directions of these responses are consistent with expectations regarding plant drought tolerance. High LDMC and LCC and low SLA are related to high investment in structural tissues, which allows plants to maintain leaf turgor under drought stress (Niinemets 2001; Chaves et al. 2002). However, the analysis of each species independently revealed that only $20 \%$ of the studied species showed significant intraspecific variability for SLA, LNC and

11 LCC in response to drought. This result is consistent with studies in which few or no significant species responses were found in leaf traits following a simulated drought (Weißhuhn et al. 2011). Moreover, the intraspecific trait responses varied in direction among species. This between-species idiosyncratic pattern corroborates previous studies exploring trait-environment relationships (Albert et al. 2010; Kichenin et al. 2013). It may arise from two main different causes. First, this can be explained by the expression of different functional trade-offs between traits. Indeed, species can combine trait responses in different ways to cope with drought (Marks \& Lechowicz 2006; West et al. 2012), which can result in a lack of convergent responses of a given trait among species. Second, trait values, as determinants of individual plant performances, may be used as a surrogate for species niche (Violle \& Jiang 2009; Kearney et al. 2010). According to this framework, trait values of a given species are expected to follow a bell-shaped response curve along environmental gradients (Violle et al. 2007). Therefore the intraspecific trait response to drought can vary

24 depending on whether drought moves species closer or away from their ecological optimum 25 (Albert et al. 2010). 
2 The variation in community mean traits revealed significant responses for LDMC, LCC and

\section{Community functional response to drought}
3 SLA. Despite the low magnitude of intraspecific variability compared to interspecific trait differences, intraspecific variability contributes significantly and sometimes much more than species turnover to the community functional response to drought. For LDMC and SLA, intraspecific variability amplified the community response mediated by species turnover, and the response of community mean LDMC was significant only when accounting for intraspecific variability. This result was even more marked for LCC, for which the increase in community mean was entirely due to intraspecific variability.

Conversely, for LNC, the significant decrease in community mean trait mediated by species turnover was dampened by the effect of intraspecific variability. Opposite contributions of species turnover and intraspecific variability to community mean LNC have been recently observed along an elevation gradient (Kichenin et al. 2013). In our study, despite a significant intraspecific increase in LNC over all species, several low-LNC species (e.g. Festuca laevigata or Cerastium arvense, L.) increased their relative abundance and highLNC species (e.g. Trifolium pratense, L.) decreased their relative abundance in response to drought. The decrease in community mean LNC mediated by species turnover can be interpreted as a filtering effect of drought that favours species with low resource acquisition strategy (i.e. 'conservative' species, Reich et al. 1999). However, the intraspecific increase in LNC suggests the existence of physiological mechanisms that allow plants to maintain resource acquisition during drought (Weih et al. 2011). This result is consistent with previous findings that phenotypic plasticity tends to maximize resource acquisition in the short term (Ryser \& Eek 2000), and supports the idea that phenotypic plasticity can differ from genetically determined interspecific trait differences (Ryser \& Eek 2000; Valladares \& Sánchez-Gómez 2006). 
It is important to point out that the low and not significant contribution of species

2 turnover to the change in community mean LDMC and LCC cannot be explained by the fact that the observed level of species turnover over the short time period of the experiment was too low to make a more important contribution. Indeed, we demonstrated that given the observed levels of species turnover and of interspecific trait differences, one might have expected (with a probability of 0.60 and 0.90 for LDMC and LCC, respectively) a much greater contribution of species turnover to the community functional response. The low contribution of species turnover to the changes in community weighted mean is due to a lack of covariation with interspecific trait differences (Lep et al. 2011). For example, the increasing abundance of high-LDMC species (e.g. Festuca laevigata) was counterbalanced by the increasing abundance of low-LDMC species (e.g. Cerastium arvense), resulting in antagonist effects on community mean LDMC. Thus, the relative contribution of inter- and intraspecific variability in the community response to drought depends on the way they are distributed with respect to species abundances and turnover. This finding provides strong support for the emerging view that whether intraspecific variability matters in community ecology does not only depend on its intensity (Albert et al. 2012).

Our results report a key role of intraspecific variability to a short-term drought event, thus providing more evidence for the importance of intrapsecific variability in the functional response of plant communities to spatial and temporal environmental heterogeneity. Such strong effect of intraspecific variability has already been reported along a narrow spatial gradient of flooding (Jung et al. 2010). On the other hand, several studies have shown that trait shifts mediated by species turnover play a strong structuring role among communities located along broad environmental gradients (Ackerly \& Cornwell 2007; Kichenin et al. 2013). Intraspecific variability may thus play a dominant role at short spatial and temporal scales. This would fit within a recent theoretical framework proposing a spatial scale- 
1 dependence of the importance of intra- vs. interspecific trait variability (Albert et al. 2012).

2 Intra- and interspecific responses could thus play complementary roles through time and

3 space scales from the short-term changes to the long-term changes (Smith et al. 2009; Sandel

4 et al. 2010), illustrating the necessity to examine both components of community trait

5 variability in order to better understand the response of trait averages to environmental

6 variability (Lep et al. 2011). The high contribution of intraspecific variability in the temporal

7 changes in community mean traits suggests that intraspecific variability can provide the

8 potential for communities to respond rapidly and reversibly to drought events through plastic

9 adjustments. In this way, intraspecific variability can promote the short-term stability of plant

communities' species composition (Lloret et al. 2012) by leading to drought adjustment

11 without requiring a strong species turnover.

Implications

14 Increasing recurrence of extreme weather events is an important component of climate change (Easterling et al. 2000; IPCC 2007). Most previous climate-changes studies using trait-based approaches have ignored intraspecific variability, relying on the assumption that intraspecific variability is much lower than between-species trait differences that underlie trait shifts due to species turnover. Analysing changes in community mean traits without accounting for intraspecific variability (e.g. by using species trait values provided by trait databases, e.g.

Kattge et al. 2011) can tremendously underestimate - or even wrongly estimate - the

21 response of communities to extreme drought events. We advocate for a better inclusion of intraspecific variability into climate-change experiments that use functional traits to understand the impact of extreme events on plant communities (Nicotra et al. 2011).

24 Modelling approaches making future projections (Scheiter \& Higgins 2009; Kearney \& Porter 2009; McMahon et al. 2011) could also benefit from more attention to intraspecific 
1 variability. Indeed, changes in species composition under climate change can be

2 overestimated if models do not allow for species adjustment through intraspecific variability. Our study underlines the role of intraspecific variability as a potentially stabilizing

4 process of plant communities after drought events. However, such stability of community 5 composition does not imply stability in ecosystem processes. Indeed, there is a growing

6 consensus that ecosystem processes are related to functional rather than species diversity

7 (Díaz \& Cabido 2001). Therefore the effect of drought on ecosystem processes should be 8 more important than expected from the simple analyses of species turnover, as community

9 trait changes are mainly driven by intraspecific variability. Further studies are needed to

10 evaluate the extent to which drought would indirectly affect ecosystem processes through

11 community functional response mediated by intraspecific variability. 


\section{Acknowledgments}

2 This research was conducted on the long term research site Zone Atelier Alpes, a member of 3 the ILTER-Europe network. ZAA publication $\mathrm{n}^{\circ} \mathrm{xxx}$. We are grateful to P.-E. Biron and to B.

4 Fourgous for access to the study area, and to G. Consoli, C. Bernard-Brunet, G. Favier, N.

5 Daumergue and C. Arnoldi for field and laboratory assistance. We thank two anonymous

6 referees as well as the Handling Editor for constructive comments on the manuscript. Marie

7 Curie International Outgoing Fellowships within the 7th European Community Framework

8 Program were supporting C.H.A. (DYVERSE project, no. 272284) and G.K. (Demo- traits 9 project, no. 299340).

\section{SUPPORTING INFORMATION}

12 Additional supporting information may be found in the online version of this article:

13

14 Table S1 Relative abundances of the studied species recorded in control plots and in drought 15 plots.

16 Fig S1 Positioning of the simulated drought on the frequency distribution of the observed 17 (1952-2009) and projected (2050-2100) June-July cumulated precipitation in the study site. 


\section{References}

2 Ackerly, D.D. (2004) Functional traits of chaparral shrubs in relation to seasonal water deficit and disturbance. Ecological Monographs, 74, 25-44.

Albert, C.H., Thuiller, W., Yoccoz, N.G., Soudan, A., Boucher, F., Saccone, P. \& Lavorel, S. (2010) Intraspecific functional variability: extent, structure and sources of variation within an alpine valley. Journal of Ecology, 98, 604-613.

Albert, C.H., de Bello, F., Boulangeat, I., Pellet, G., Lavorel, S. \& Thuiller, W. (2012) On the importance of intraspecific variability for the quantification of functional diversity. Oikos, 121, 116-126.

Andersen, K.M., Endara, M.J., Turner, B.L. \& Dalling, J.W. (2012) Trait-based community assembly of understory palms along a soil nutrient gradient in a lower montane tropical forest. Oecologia, 168, 519-531.

Buckland, S.M., Grime, J.P., Hodgson, J.G. \& Thompson, K. (1997) A comparison of plant responses to the extreme drought of 1995 in Northern England. Journal of Ecology, 85, 875-882.

Chase, J.M. (2007) Drought mediates the importance of stochastic community assembly. Proceedings of the National Academy of Sciences USA, 104, 17430-17434.

Chaves, M.M., Pereira, J.S., Maroco, J., Rodrigues, M.L., Ricardo, C.P.P., Osorio, M.L., Carvalho, I., Faria, T. \& Pinheiro, C. (2002) How plants cope with water stress in the field: photosynthesis and growth. Annals of Botany, 89, 907-916.

Cornwell, W.K. \& Ackerly, D.D. (2009) Community assembly and shifts in the distribution of functional traits values across an environmental gradient in coastal California. Ecological Monographs, 79, 109-126.

Díaz, S. \& Cabido, M. (2001) Vive la difference: Plant functional diversity matters to ecosystem processes. Trends in Ecology and Evolution, 16, 646-655. 
1 Easterling, D.R., Meehl, G.A., Parmesan, C., Changnon, S.A., Karl, T.R. \& Mearns, L.O. (2000) Climate extremes: observations, modeling, and impacts. Science, 289, 2068-2074.

Evans, S.E., Byrne, K.M., Lauenroth, W.K. \& Burke, I.C. (2011) Defining the limit to resistance in a drought-tolerant grassland: long-term severe drought significantly reduces the dominant species and increases ruderals. Journal of Ecology, 99, 1500-1507. Biology, 17, 2002-2011.

Garnier, E., Shipley, B., Roumet, C. \& Laurent, G. (2001a) A standardized protocol for the determination of specific leaf area and leaf dry matter content. Functional Ecology, 15,

Garnier, E., Laurent, G., Bellmann, A., Debain, S., Berthelier, P., Ducout, B., Roumet, C. \& Navas, M.-L. (2001b) Consistency of species ranking based on functional leaf traits. New Phytologist, 152, 69-83.

Garnier, E., Cortez, J., Billès, G., Navas, M.-L., Roumet, C., Debussche, M., Laurent, G., 2637.

Grime, J.P., Fridley, J.D., Askew, A.P., Thompson, K., Hodgson, J.G. \& Bennett, C.R. (2008) Long-term resistance to simulated climate change in an infertile grassland. Proceedings of the National Academy of Science, 105, 10028-10032.

Helmuth, B., Kingsolver, J.G. \& Carrington, E. (2005) Biophysics, physiological ecology, 
1 Hudson, J.M.G., Henry, G.R.H. \& Cornwell, W.K. (2011) Taller and larger: shifts in Arctic tundra leaf traits after 16 years of experimental warming. Global Change Biology, 17, 1013-1021.

IPCC (2007) Climate change 2007: The Physical Science Basis. Contribution of Working Group I to the Fourth Assessment Report of the Intergovernemental Panel on Climate Change. Cambridge University Press, Cambridge, UK.

Jentsch, A., Kreyling, J. \& Beierkuhnlein, C. (2007) A new generation of climate-change experiments: Events, not trends. Frontiers in Ecology and the Environment, 5, 365-374.

Jump, A.S. \& Peñuelas, J. (2005) Running to stand still: adaptation and the response of plants to rapid climate change. Ecology Letters, 8, 1010-1020.

Jung, V., Violle, C., Mondy, C., Hoffmann, L. \& Muller, S. (2010) Intraspecific variability and trait-based community assembly. Journal of Ecology, 98, 1134-1140.

Kattge, J., Díaz, S., Lavorel, S., Prentice, I.C., Leadley, P. et al. (2011) TRY - a global database of plant traits. Global Change Biology, 17, 2905-2935.

Kearney, M. \& Porter, W. (2009) Mechanistic niche modelling: combining physiological and spatial data to predict species' ranges. Ecology Letters, 12, 334-350.

Kearney, M., Simpson, S.J., Raubenheimer, D. \& Helmuth, B. (2010) Modelling the ecological niche from functional traits. Philosophical Transactions of the Royal Society B, 365, 3469-3483.

Kichenin, E., Wardle, D.A., Peltzer, D.A., Morse, C.W. \&Freschet, G.T. (2013) Contrasting effects of plant inter- and intraspecific variation on community-level trait measures along an environmental gradient. Functional Ecology, 27, 1254-1261.

Klotz, S., Kühn, I. \& Durka, W. (2002) BIOLFLOR - Eine Datenbank zu biologischökologischen Merkmalen der Gefäßpflanzen in Deutschland. Schriftenreihe für Vegetationskunde, 38. Bundesamt für Naturschutz, Bonn. 
1 Kreyling, J., Jentsch, A. \& Beierkuhnlein, C. (2011) Stochastic trajectories of succession initiated by extreme climatic events. Ecology Letters, 14, 758-764.

Lavorel, S., Grigulis, K., McIntyre, S., Garden, D., Williams, N., Dorrough, J., Berman, S., Quétier, F., Thébault, A., \& Bonis, A. (2008) Assessing functional diversity in the field methodology matters! Functional Ecology, 22, 134-147.

Lep , J., de Bello, F., milauer, P. \& Dole al, J. (2011) Community trait response to environment: disentangling species turnover vs intraspecific trait variability effects. Ecography, 34, 856-863.

Levy, E.B. \& Madden, E.A. (1933) The point method of pasture analysis. New Zealand Journal of Agriculture, 46, 267-279.

Lloret, F., Escudero, A., Iriondo, J.M., Martínez-Vilalta, J. \& Valladares, F. (2012) Extreme climatic events and vegetation: the role of stabilizing processes. Global Change Biology, 18, 797-805.

Marks, C.O. \& Lechowicz, M.J. (2006) Alternative designs and the evolution of functional diversity. American Naturalist, 167, 55-67.

McMahon, S.M., Harrison, S.P., Armbruster, W.S., Bartlein, P.J., Beale, C.M., Edwards, M.E., Kattge, J., Midgley, G., Morin, X. \& Prentice, I.C. (2011) Improving assessment and modelling of climate change impacts on global terrestrial biodiversity. Trends in Ecology \& Evolution, 26, 249-259.

Meehl, G.A. \& Tebaldi, C. (2004) More intense, more frequent, and longer lasting heat waves in the 21st century. Science, 305, 994-997.

22 Messier, J., McGill, B.J. \& Lechowicz, M.J. (2010) How do traits vary across ecological scales? A case for trait-based ecology. Ecology Letters, 13, 838-848. 
1 Nicotra, A.B., Atkin, O.K. , Bonser, S.P., Davidson, A.M., Finnegan, E.J., Mathesius, U.,

2 Poot, P., Purugganan, M.D., Richards C.L., Valladares F. \& van Kleunen, M. (2011) Plant

3 phenotypic plasticity in a changing climate. Trends in Plant Science, 15, 684-692.

4 Niinemets, U. (2001) Global-scale climatic controls of leaf dry mass per area, density, and

Poorter, H., Niinemets, Ü., Poorter, L., Wright, I.J. \& Villar, R. (2009) Causes and consequences of variation in leaf mass per area (LMA): a meta-analysis. New Phytologist, 182, 565-588.

R Development Core Team (2010) R: A Language and Environment for Statistical Computing. R Foundation for Statistical Computing, Vienna, Austria.

Reich, P.B., Ellsworth, D.S., Walters, M.B., Vose, J.M., Gresham, C., Volin, J.C. \& Bowman, American Journal of Botany, 87, 402-411.

Sandel, B., Goldstein, L.J., Kraft, N.J.B., Okie, J.G., Shuldman, M.I., Ackerly, D.D., Cleland, E.E. \& Suding, K.N. (2010) Contrasting trait responses in plant communities to

Ryser, P. \& Eek, L. (2000) Consequences of phenotypic plasticity vs. interspecific differences W.D. (1999) Generality of leaf trait relationships: a test across six biomes. Ecology, 80, 1955-1969. experimental and geographic variation in precipitation. New Phytologist, 188, 565-575.

Scheiter, S. \& Higgins, S.I. (2009) Impacts of climate change on the vegetation of Africa: an adaptive dynamic vegetation modelling approach. Global Change Biology, 15, 22242246. 
1 Smith, M.D. (2011) The ecological role of climate extremes: current understanding and future prospects. Journal of Ecology, 99, 651-655.

Smith, M.D., Knapp, A.K. \& Collins, S.L. (2009) A framework for assessing ecosystem dynamics in response to chronic resource alterations induced by global change. Ecology, 90, 3279-3289.

Theurillat, J.-P. \& Guisan, A. (2001) Potential impact of climate change on vegetation in the European Alps: a review. Climatic Change, 50, 77-109.

Valladares, F. \& Sánchez-Gómez, D. (2006) Ecophysiological traits associated with drought in Mediterranean tree seedlings: Individual responses versus interspecific trends in eleven species, Plant Biology, 8, 688-697.

Violle, C., Navas, M.-L., Vile, D., Kazakou, E., Fortunel, C., Hummel, I. \& Garnier, E. (2007) Let the concept of trait be functional! Oikos, 116, 882-892.

Violle, C. \& Jiang, L. (2009) Towards a trait-based quantification of species niche. Journal of Plant Ecology, 2, 87-93.

Violle, C., Enquist, B.J., McGill, B.J., Jiang, L., Albert, C.H., Hulshof, C., Jung, V. \& Messier, J. (2012) The return of the variance: intraspecific variability in community ecology. Trends in Ecology and Evolution, 27, 244-252.

Volaire, F. (2008) Plant traits and functional types to characterise drought survival of plurispecific perennial herbaceous swards in Mediterranean areas. European Journal of Agronomy, 29, 116-124.

Weih, M., Bonosi, L., Ghelardini, L. \& Rönnberg-Wästljung, A.C. (2011) Optimizing nitrogen economy under drought: increased leaf nitrogen is an acclimation to water stress in willow (Salix spp.). Annals of Botany, 108, 1347-1353.

Weißhuhn, K., Auge, H. \& Prati, D. (2011) Geographic variation in the response to drought in nine grassland species. Basic and Applied Ecology, 12, 21-28. 
1 West, A.G., Dawson, T.E., February, E.C., Midgley, G.F., Bond, W.J. \& Aston, T.L. (2012)

2 Diverse functional responses to drought in a mediterranean-type shrubland in South Africa. New Phytologist, 195, 396-407.

4 Wright, I.J., Reich, P.B. \& Westoby, M. (2001) Strategy shifts in leaf physiology, structure

5 and nutrient content between species of high- and low-rainfall and high- and low-nutrient

6 habitats. Functional Ecology, 15, 423-434.

7 
1

2

3

4

5

6

7

8

10

11

12

13

14

15

16

17

18

19

20

21

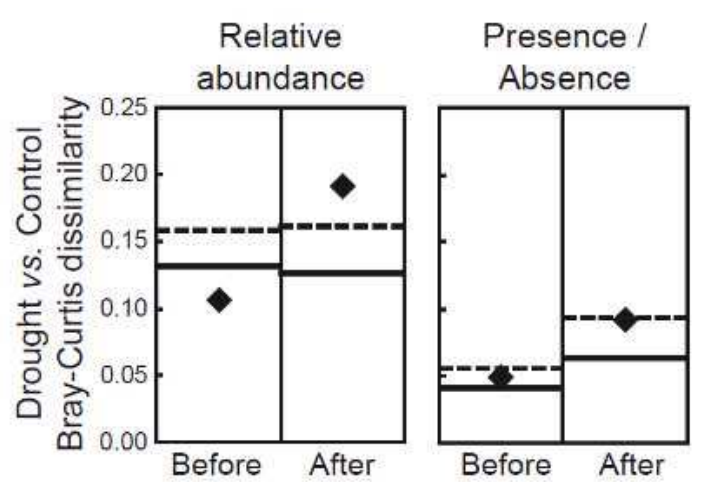

Fig 1 Bray-Curtis dissimilarity between drought plots and control plots before and after the simulated drought event, calculated from relative abundance data (left) and from presence/absence (right). Diamonds indicate observed Bray-Curtis dissimilarity values; solid and doted lines indicate respectively the median and the $95 \%$ percentile of a null distribution obtained from 10000 permutations. 


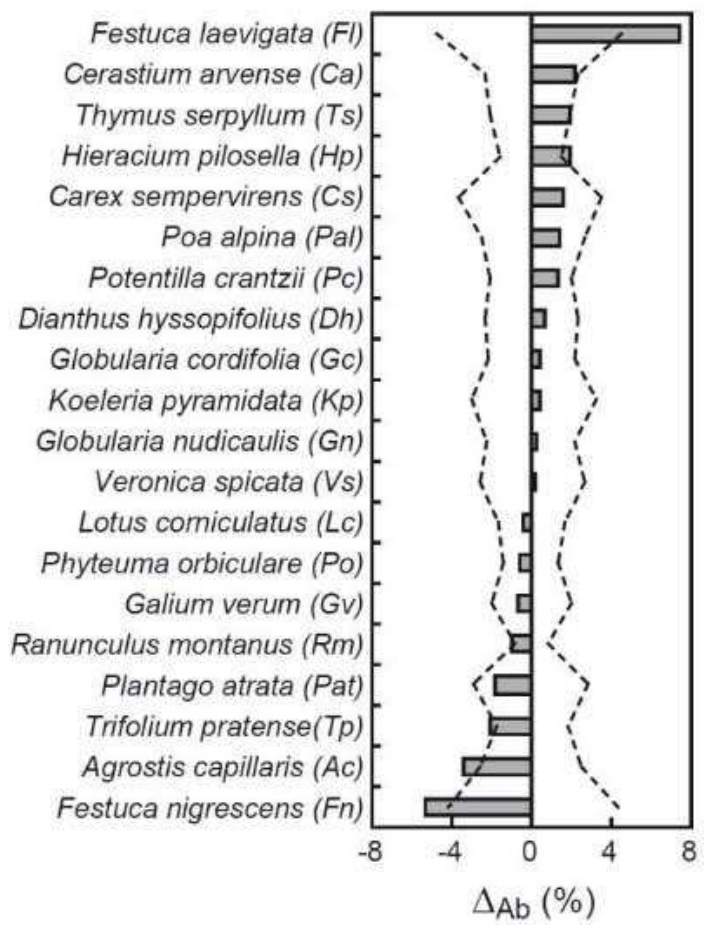

Fig 2 Difference in the relative abundance ( $\mathrm{Ab}$ ) of each species in control vs. drought plots. Bars indicate the observed differences and doted lines indicate the 2.5\% and $97.5 \%$ percentiles of a null distribution obtained from 10000 permutations. Species are ordered according to their change in relative abundance. Only the 20 most abundant species are shown, i.e. the species on which leaf traits were measured. 
1

2

3

4

5

6

7

8

10

11

12

13

14

15

16

17

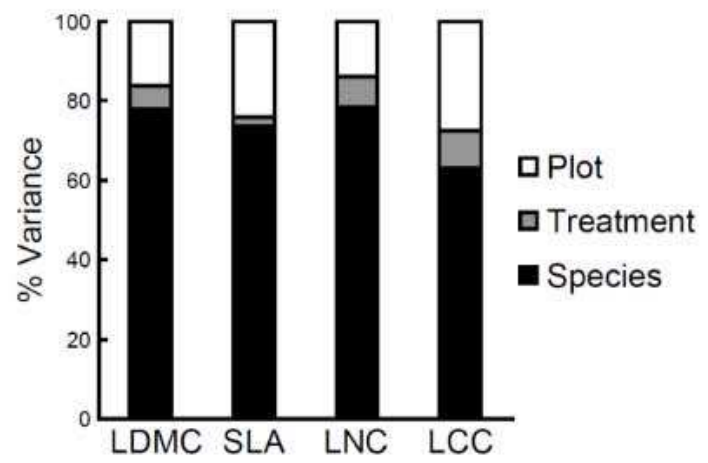

Fig 3 Relative variance decomposition of leaf dry matter content (LDMC), specific leaf area (SLA), leaf nitrogen concentration (LNC) and leaf carbon concentration (LCC) at the plot (i.e. intraspecific trait variability within treatments), treatment (i.e. intraspecific trait variability between treatments) and species (i.e. between-species trait variability) levels. 

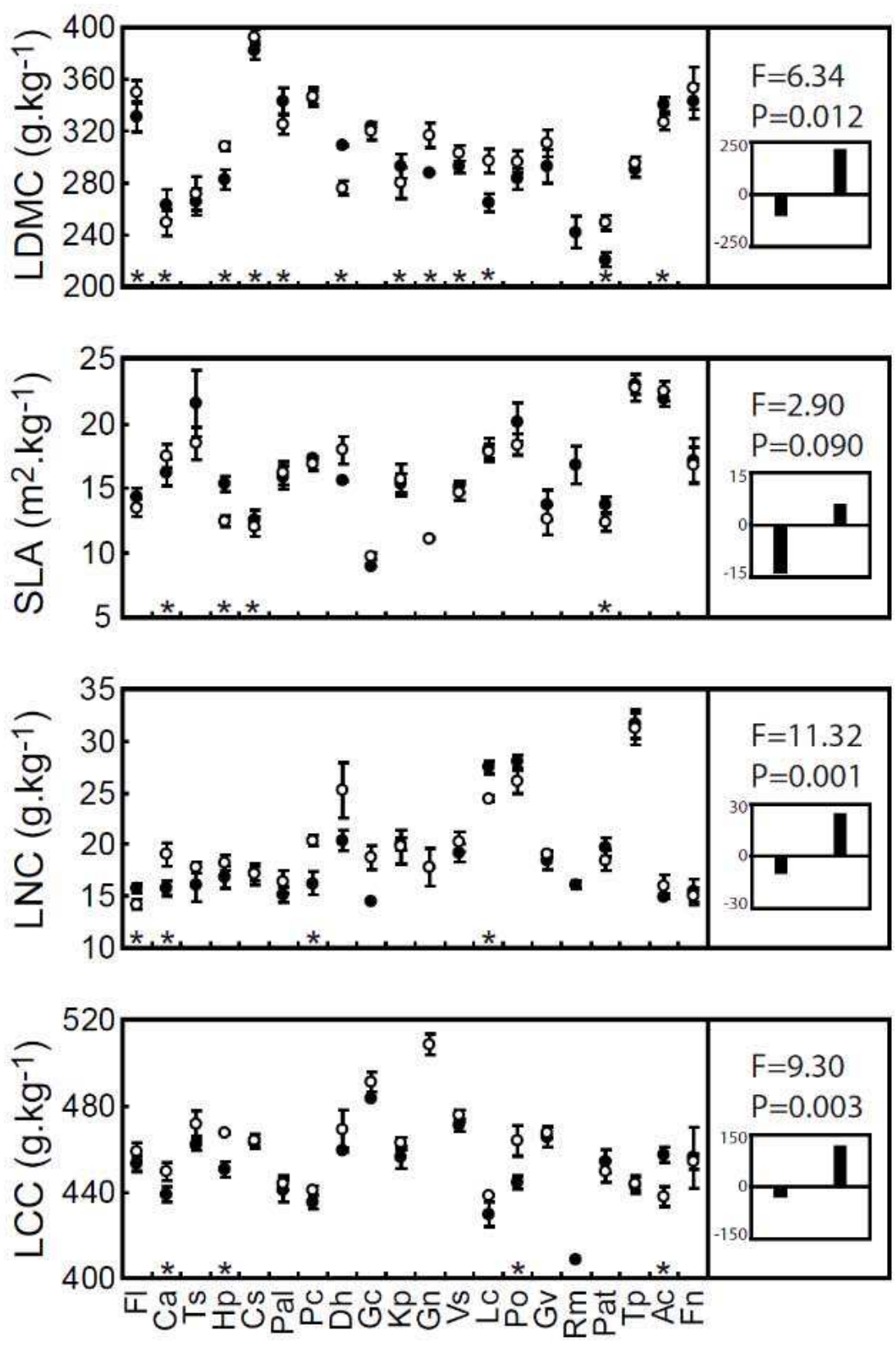

Fig 4 Leaf trait responses to drought for each species. Data are means \pm standard deviations of leaf dry matter content (LDMC), specific leaf area (SLA), leaf nitrogen concentration (LNC) and leaf carbon concentration (LCC) in control plots (closed symbols) and in drought plots (open symbols). Species are ordered in the same way as in Fig. 2, i.e. in decreasing order of their change in relative abundance (see Fig. 2 for species names). Asterisks indicates significant differences between drought plots and control plots $(P<0.05)$ for each species. Insets at the right of each graph represent the cumulated decrease (left bar) and increase (right bar) of trait values over all species in response to drought, and therefore indicate the prevailing trends of trait responses. The statistical results for the effect of drought over all species are given above the insets. 

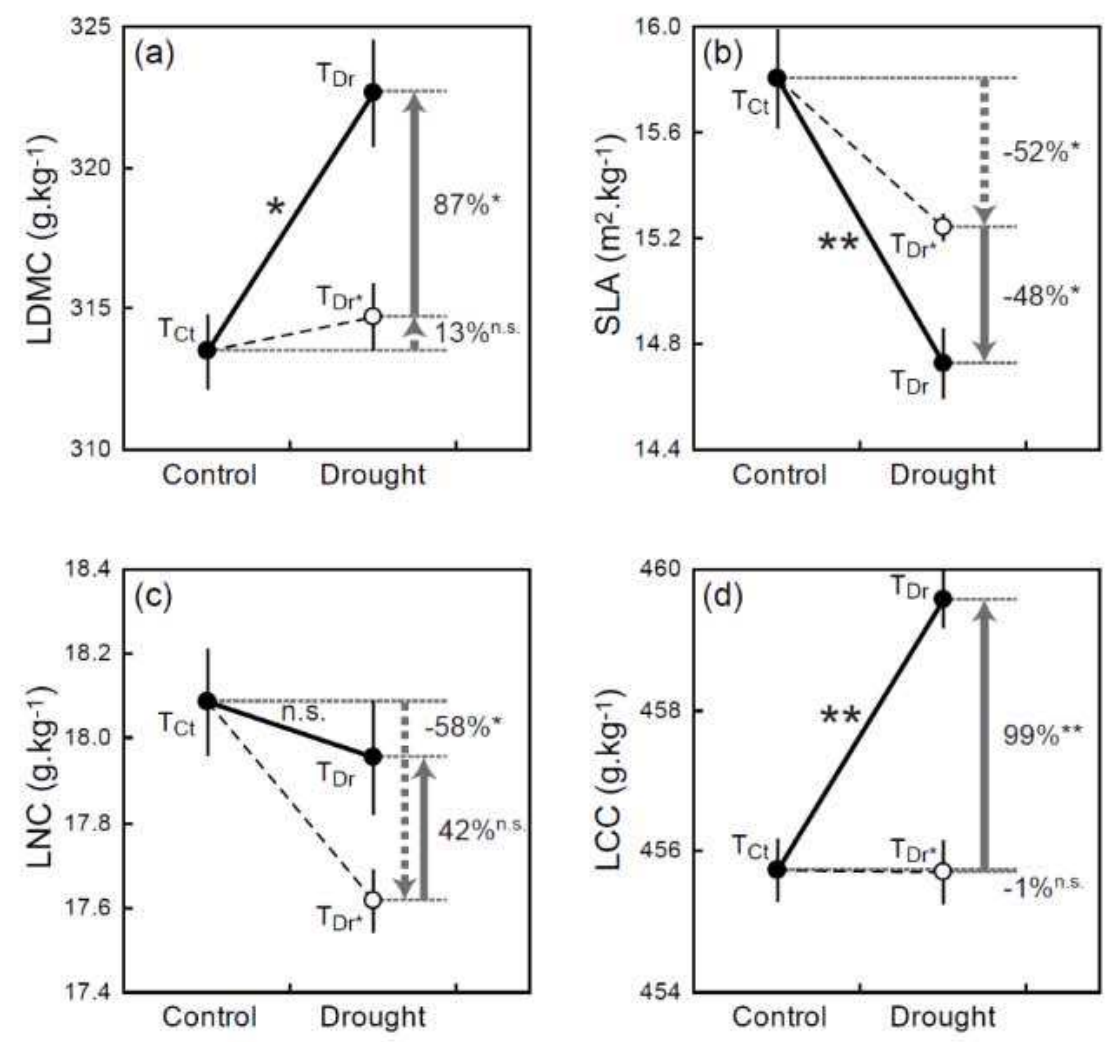

Fig 5 Changes in community weighted mean trait values due to both species turnover and intraspecific variability (solid line) and due to species turnover only (dashed line). $\mathrm{T}_{\mathrm{Ct}}$ and $\mathrm{T}_{\mathrm{Dr}}$ correspond to the observed community mean traits in control plots and in drought plots; $\mathrm{T}_{\mathrm{Dr}^{*}}$ corresponds to the community mean trait in drought plots recalculated from trait values measured in control plots. Data are means \pm standard errors of community means of LDMC (a), SLA (b), LNC (c) and LCC (d). Arrows indicate the contributions of species turnover ( $\mathrm{C}_{\text {Turn }}$; dashed-line arrows) and of intraspecific variability $\left(\mathrm{C}_{\text {Intra }}\right.$; solid-line arrows) to the changes in community mean traits. $\mathrm{C}_{\text {Tum }}$ and $\mathrm{C}_{\text {Intra }}$ are expressed as percentages of their cumulative magnitude (Significance levels: ${ }^{*} P<0.05$, ${ }^{*} * P<0.01$, n.s. not significant). 
LDMC
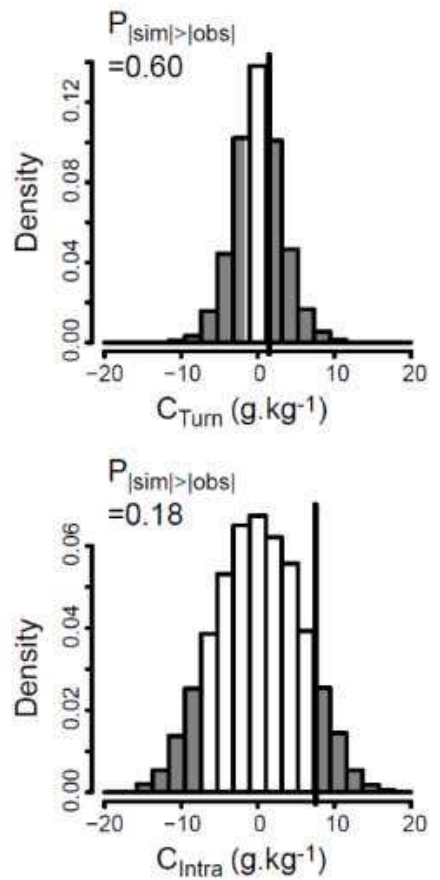

SLA

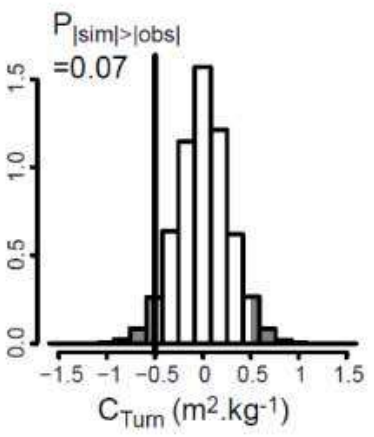

$P_{\mid \text {sim|>|obs| }}$

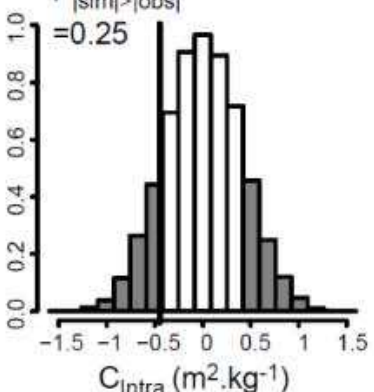

LNC
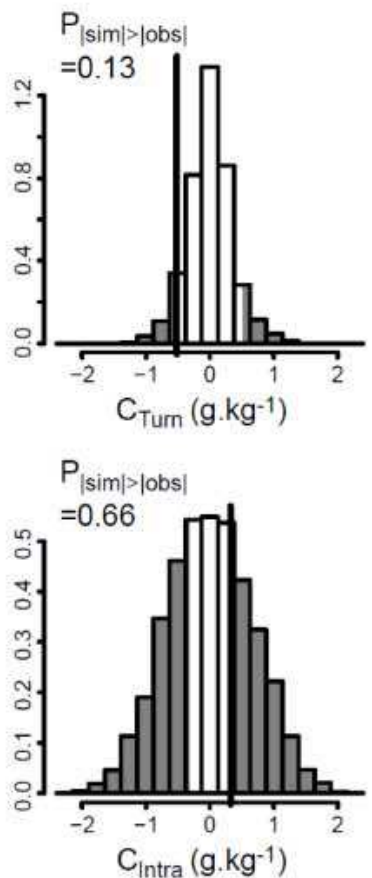

LCC

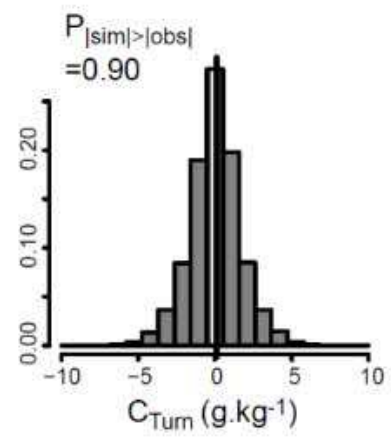

$\mathrm{P}_{\mid \text {sim|>|obs| }}$

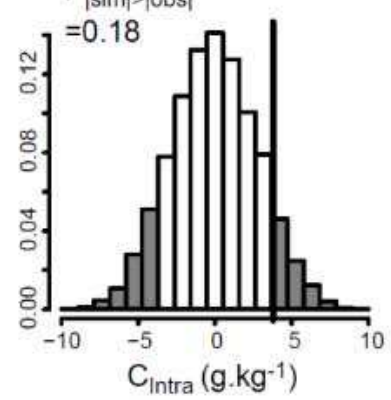

Fig 6 Observed vs. simulated contribution of species turnover $\left(\mathrm{C}_{\mathrm{Turn}}\right)$ and of intraspecific variability $\left(\mathrm{C}_{\text {Intra }}\right)$ to the change in community mean LDMC, SLA, LNC and LCC in response to drought. Each histogram represents the distribution of 10000 simulated values of $\mathrm{C}_{\text {Turn }}$ or of $\mathrm{C}_{\text {Intra }}$, resulting from random reallocations of species traits to species abundances. Thick lines indicate the observed contributions of turnover or of intraspecific variability. For each graph, the shaded area (and the associated proportion $\mathrm{P}_{|\operatorname{sim}|-\mid \text { obs } \mid}$ ) indicates the portion of the distribution where the simulated contributions are higher, in magnitude, than the observed contribution. 


\section{Figure S1}

Positioning of the simulated drought on the frequency distribution of the observed (19522009) and projected (2050-2100) June-July cumulated precipitation in the study site.

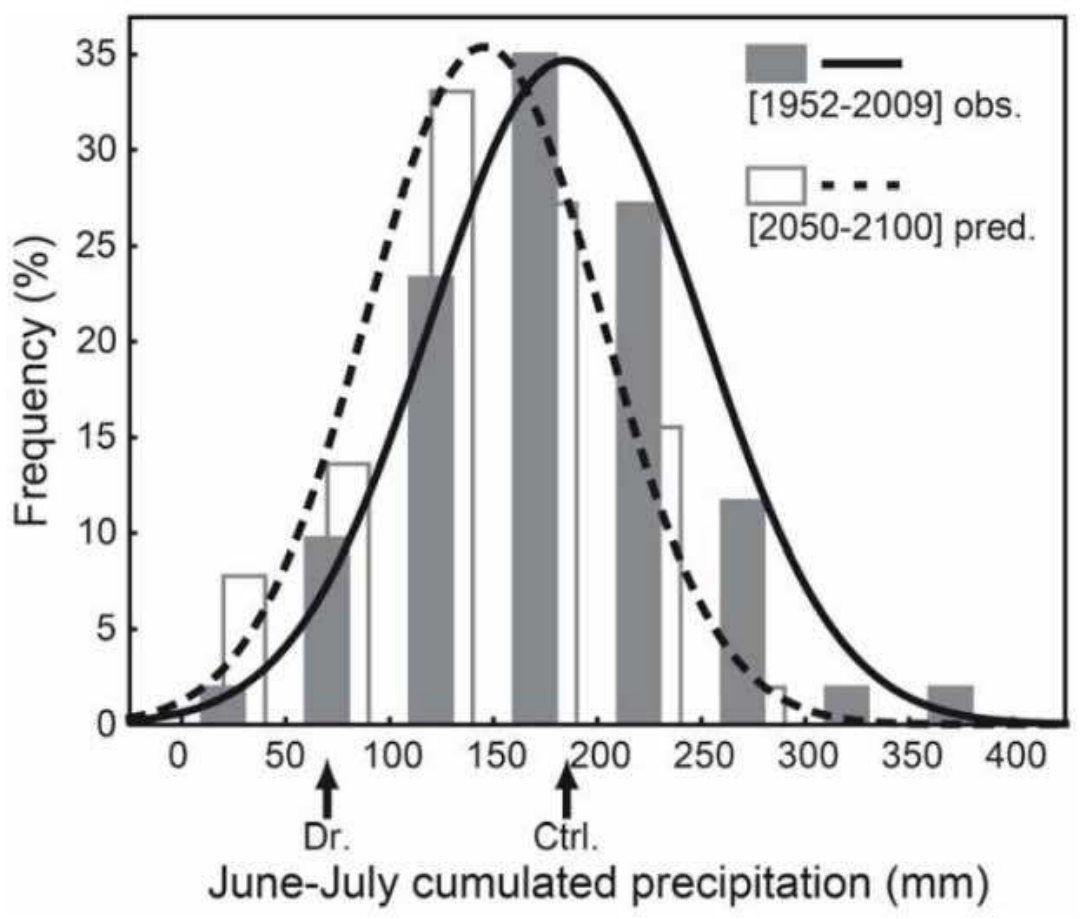

Figure S1 Frequency distribution of the observed June-July cumulated precipitation in the study site observed over the 1952-2009 period (data: Météo-France, grey) and predicted for the 2050-2100 period under the B1 scenario (Hadley Centre model HADCM3, white). Curves correspond to fitted normal distributions. Precipitations simulated in the control (Ctr.) and the dry (Dr.) treatments are indicated on the $\mathrm{x}$ axis. 


\section{Table S1}

Relative abundances of the studied species recorded in control plots and in drought plots.

Table S1 Relative abundances of the species sampled for trait measurements, in control plots and in drought plots during the second survey (15-16 July 2010, after the simulated drought event).

\begin{tabular}{lcc}
\hline Species & \multicolumn{2}{c}{ Relative abundance (\%) } \\
& Control & Drought \\
\hline Carex sempervirens & 14,0 & 15,0 \\
Festuca laevigata & 12,9 & 19,9 \\
Festuca nigrescens & 12,1 & 6,1 \\
Plantago atrata & 9,3 & 7,0 \\
Koeleria pyramidata & 7,4 & 7,6 \\
Veronica spicata & 6,9 & 6,7 \\
Agrostis capillaris & 6,5 & 2,7 \\
Galium verum & 4,7 & 3,7 \\
Cerastium arvense & 4,0 & 6,1 \\
Trifolium pratense & 3,9 & 1,7 \\
Potentilla crantzii & 3,3 & 4,6 \\
Poa alpina & 3,2 & 4,5 \\
Lotus corniculatus & 2,6 & 2,0 \\
Dianthus hyssopifolius & 2,0 & 2,6 \\
Phyteuma orbiculare & 1,6 & 1,0 \\
Thymus serpyllum & 1,6 & 3,5 \\
Globularia cordifolia & 1,2 & 1,6 \\
Globularia nudicaulis & 1,2 & 1,3 \\
Ranunculus montanus & 1,1 & 0,0 \\
Hieracium pilosella & 0,5 & 2,4 \\
\hline
\end{tabular}

